\title{
MEMÓRIA E HISTÓRIA DA ESQUERDA: a organização da massa trabalhadora em São Paulo (Brasil)
}

\author{
Alzira Lobo de Arruda Campos* \\ Marília Gomes Ghizzi Godoy** \\ Rafael Lopes de Souza***
}

\begin{abstract}
RESUMO: O estudo da esquerda na cidade de São Paulo vincula-se ao estudo do movimento operário na sua versão mais consequente - a do sindicalismo. Os combates operários e a luta sindical constituíram a caixa de ressonância da organização da vanguarda revolucionária, isto é, dos partidos ou correntes que pretendiam a derrubada da ordem burguesa, anunciando a coesão social nos âmbitos dos sindicatos e dos partidos políticos nacionais. Embora incontestavelmente sob a influência de teóricos e partidos europeus, cada corrente de esquerda era prisioneira da história brasileira, da história de São Paulo e, em última instância, das relações pessoais estabelecidas entre seus quadros. Nesse sentido, as interações do PCB com o ambiente nacional, estudadas como predeterminações para muitas atividades e posições dos comunistas, devem ser acrescidas com os laços de amizade, que se revelaram fundamentais nas origens da organização operária em nossa história.
\end{abstract}

PALAVRAS-CHAVE: Memória, Sindicalismo; Anarquistas e Comunistas.

\section{Memory and History of the Left: the organization of the working mass in São Paulo (Brazil)}

ABSTRACT: The study of the left-wing party in the city of São Paulo is linked to the study of the labor movement in its more fundamental version - the syndicalism. The labor fights and the syndical struggle constituted the box of resonance of the of the revolutionary vanguard organization, that is, of the parties or movements which aspired the fall of the bourgeois order, announcing the social cohesion in the scope of the syndicates and of the national political parties. Although unquestionably under the influence of theorists and European parties, each left-wing movement was a prisoner of the Brazilian history, the history of São Paulo and, in last instance, of the personal relations established among their participants. In this sense, the interactions of PCB with the national environment, studied as predeterminations for many activities and communist positions, must be summed to the bonds of friendship, which showed up as essential in the origins of the working class organization in our history.

KEYWORDS: Memory, Syndicalism; Anarchists and Communists.

\section{Memoria y Historia de la izquierda: la organización de la masa trabajadora en São Paulo (Brasil)}

RESUMEN: El estudio de la izquierda en la ciudad de São Paulo se enlaza al estudio del movimiento obrero en su versión más relevante - la del sindicalismo. Los combates obreros y la lucha sindical constituyeron la caja de resonáncia de la organización de la vanguardia revolucionaria, és decir, de los partidos o corrientes que pretendían el derrocamiento del orden burguesa, anunciando la cohesión social en los ámbitos de los sindicatos y de los partidos políticos nacionales. Aunque indiscutiblemente bajo la influencia de teóricos y partidos europeos, cada corriente de izquierda era prisionera de la historia brasileña, de la historia de São Paulo y, en última instancia, de las relaciones personales establecidas entre sus cuadros. En este sentido, las interacciones del PCB con el ambiente nacional, estudiadas como predeterminaciones para muchas actividades y posiciones de los comunistas, deben ser añadidas con los lazos de amistad, que se manifestaron como fundamentales en las orígenes de la organización obrera en nuestra historia.

PALABRAS-CLAVE: Memoria, Sindicalismo; Anarquistas y Comunistas.

\footnotetext{
* Doutora em História pela Universidade de São Paulo, livre-docente em Metodologia da História (UNESP); Docente do Programa em Ciências Humanas, nível Mestrado (UNISA); email: loboarruda@hotmail.com ** Doutora em Psicologia Social pela Pontifícia Universidade de São Paulo, docente do Programa em Ciências Humanas, nível Mestrado (UNISA); email: mgggodoy@yahoo.com.br

*** Doutor em História Social pela Universidade Estadual de Campinas (UNICAMP). Docente do Programa em Ciências Humanas, nível Mestrado (UNISA). Contato: Rua Isabel Schmidt No 349, Santo Amaro, CEP 04743-030, São Paulo-SP, Brasil. E-mail: canoeiros2008@gmail.com.
} 
Chilcote ${ }^{1}$, como historiador, e Brandão ${ }^{2}$, como militante/memorialista, reconhecem que a história do Partido Comunista do Brasil é prisioneira da própria história do partido. História essa que se iniciou em datas muito anteriores à da fundação do partido. Na verdade, trata-se de mais um capítulo, que se pensava então como definitivo, da longa luta entre o capital e o trabalho, particularmente feroz na exploração de trabalhadores de um país, marcado por quatro séculos de escravismo. Nesses tempos heroicos, os sindicatos eram dominados pelos anarco-sindicalistas e pelos socialistas, mobilizados para diminuir a extrema miséria dos trabalhadores e desenvolver neles uma consciência de classe, propícia a uma revolução social. Nas décadas de 1920-30, os comunistas entraram no meio sindical, especialmente por meio de seus dissidentes, os trotskistas, então pertencentes à Liga Comunista, considerada como uma fração do partido. Os embates violentos para o controle da massa trabalhadora, como plataforma necessária ao comando da revolução proletária, criaram uma documentação polifônica, na qual se ouvem as vozes dos sindicalistas, de mistura com os anarco-sindicalistas, socialistas, stalinistas e trotskistas, entre outros. Nessa Torre de Babel estão também as vozes da reação, por meio dos agentes da polícia política de Vargas, aliados claramente à burguesia. $\mathrm{O}$ aparelhamento policial do Estado significou o aparelhamento também dos sindicatos, ministerializando-os, reduzindo-os à condição de "chapas-brancas" do governo ditatorial ${ }^{3}$. A crise do sindicalismo no Brasil, considerada como decorrente da era neoliberal, nos anos 90 do último século, com o esvaziamento da perspectiva classista dos sindicatos, que passaram da "confrontação à cooperação conflitiva" ${ }^{4}$, possui um antecedente histórico nos "sindicatos amarelos" dos tempos de Vargas.

A fim de enriquecer a reflexão a respeito desse ponto-chave da visão teórica das relações dos partidos políticos com os sindicatos, analisam-se possíveis peculiaridades da seção paulista do PCB, nos seus anos heroicos de formação, quando dissidentes, no quadro partidário, competiam com as demais correntes de esquerda para a formação da vanguarda da revolução proletária. O prisma desta análise prende-se, necessariamente, às raízes históricas das dissidências, ou às "falhas e debilidades" dos primeiros passos do PCB. Estudos e documentos sobre o assunto ressaltam como peculiaridades nitidamente paulistanas a forte influência da organização sindical nas massas operárias e a participação de imigrantes nos partidos de esquerda.

As memórias operárias referentes a São Paulo afirmam que foi a exacerbação das injustiças praticadas e da exploração salarial o maior aliciante para forçar o trabalhador a se agrupar e unir, dando início às reivindicações, e criando nele a consciência dos seus direitos. 
Para tanto, o trabalho de um pequeno grupo de operários socialistas e anarquistas aproveitou-se com inteligência de todas as ocasiões de descontentamento que se manifestavam, imprimindo boletins e distribuindo-os entre os trabalhadores, realizando reuniões em suas casas, nas quais lhes transmitiam que a subordinação operária era produto de uma organização social baseada em privilégios de classe. ${ }^{5}$ Tratava-se de substituir o fundamento das reivindicações sociais que se referia à melhor ou pior situação da classe explorada, pela ideia-chave do marxismo: a existência de duas classes antagônicas, cujo desaparecimento é essencial para o fim da exploração do homem pelo homem. Embora o melhoramento das condições de vida dos trabalhadores continuasse a ser uma das aspirações imediatas do PCB, ele deixou de ser a determinante de seus processos táticos e dos seus princípios ideológicos. ${ }^{6}$

Do ponto de vista teórico, a grande discussão travada pela vanguarda revolucionária e pelos agentes do statu quo, nos dois decênios iniciais do século XX, centrava-se na afirmação/negação da paz social. Até 1919, políticos e jornalistas diziam que as greves eram obra de agitadores profissionais, na sua maior parte estrangeiros, perturbadores da ordem. Nesse ano, 100.000 trabalhadores entraram "em parede na Paulicéia" 7 , provocando o pânico entre os detentores do poder. Epitácio Pessoa, que assumiu a presidência da República em julho de 1919, muniu-se de um esquema que dividia os trabalhadores em dois campos: o nacional, governista e reformista; o estrangeiro, anarquista e anarco-sindicalista. Munido desse esquema, encheu as prisões de operários, multiplicou violências e deportou para Portugal, Espanha e Itália perto de 100 militantes estrangeiros. ${ }^{8}$

\section{"Paredes" e greves dos trabalhadores: ação e reação}

O movimento grevista dos trabalhadores gráficos de 1929, duramente reprimido pela polícia, ressaltou os antagonismos de classe, levando as facções em luta ao estado decisivo em que os combatentes tomam posições definidas para lançar numa batalha mais violenta os seus interesses irreconciliáveis.

Essas análises foram consequentes e posteriores às conquistas trabalhistas que, nos vinte primeiros anos do último século, produziram-se por intermédio de longas lutas, nas quais os operários declararam-se em greve em razão das condições insuportáveis de trabalho e não especificamente por posições ideológicas. Estas foram sendo afirmadas e confirmadas no decorrer dos movimentos operários, pelas lideranças de esquerda - anarquistas e socialistas que se puseram à frente dos grevistas, convidadas, muitas vezes, para participar das negociações entre as partes em dissídio. 
Em 1889 a imprensa paulista registra que as "paredes" estavam contagiando todas as classes proletárias, como moda importada da Europa ${ }^{9}$. Entretanto, a mesma imprensa reconhece que as agitações operárias eram motivadas por baixos salários, carestia de vida e condições trabalhistas intoleráveis: "Os gêneros de primeira necessidade, carne, feijão e todos os alimentícios têm subido tanto de preço, que as classes operárias e pobres estão quase privadas deles" $" 10$.

O problema da carestia de vida, no ano de 1889 e nos subsequentes, era vinculado a dois fatores: ao emissionismo e ao aumento na procura de gêneros alimentícios provocado pela introdução de massas sucessivas de imigrantes, pela lavoura paulista. ${ }^{11}$

Em 1. ${ }^{\circ}$ de maio de 1898, Paschoal Artese lançou o jornal O Proletário, com Francisco Escobar e Euclides da Cunha como redatores. Euclides da Cunha publicou, no número de estreia, o programa de 21 itens (tribunais trabalhistas, oito horas de trabalho, racionalização do crédito, substituição das forças armadas pelo povo armado, etc.) e uma mensagem destinada a "promover a solidariedade entre todos os que formam a imensa maioria dos oprimidos sobre os quais pesam as grandes injustiças". No fim do século passado, entraram no Brasil dois dos maiores líderes trabalhistas da época: Gigi Damiani e Oreste Ristori. ${ }^{12}$.

O ano de 1901 assinalou amplos movimentos operários na capital paulista. Vidreiros na maioria franceses - recusaram-se a receber salários em francos em lugar de mil-réis, o que deveria acontecer a partir de $1 .^{\circ}$ de março de 1901. As condições de trabalho dos vidreiros eram particularmente dramáticas. Com o apoio dos socialistas, o movimento dos vidreiros contra o pagamento em francos foi vitorioso. ${ }^{13}$

\section{Sindicatos e luta pela tomada de consciência de classe: a solidariedade operária}

As lutas operárias e as organizações associativas e sindicais operárias constituíram uma espécie de back ground da história da fundação do PCB e de sua seção paulista. Em 1920 já existia, nas principais cidades brasileiras, perto de um milhar de sindicatos ou de associações congêneres, de quase todas as categorias profissionais. A luta e a organização operárias acompanhavam-se de órgãos de imprensa própria, dominada por ideias libertárias ou liberais, até as grandes greves de 1917/18. Nesses jornais, a palavra "classe" ainda não tinha significado definido, embora eles defendessem as ideologias operárias em voga - o anarquismo e o anarcosindicalismo -, inspiradas nas ideias de Bakunin, Kropotkin, Proudhon, Faure. Se, de um lado, essas ideias eram úteis para unir e organizar os operários, do outro tinham o defeito de isolar o operariado da vida política, que consideravam como uma invenção burguesa. Restringiam, 
assim, sua atividade à luta por reivindicações econômicas, à espera de que um dia a Revolução pendurasse os tiranos, os padres e capitalistas nos postes, para instaurar o anarquismo - um hipotético regime social sem governo. ${ }^{14}$ No ano de 1919 , maximalistas e anarquistas brasileiros fundaram no Rio o Partido Comunista Libertário, declarando-se " inimigos irreconciliáveis do Coletivismo e do Socialismo de Estado, que, tendendo à destruição dos privilégios capitalistas, criam, inevitavelmente, os privilégios burocratas". 15 O grupo anarquista do Rio de Janeiro, responsável pela criação do Grupo Comunista de 1921-1922 e pelo Partido Comunista, transferiu-se quase todo para São Paulo. ${ }^{16}$

Em 16 de fevereiro de 1901, revoltadas com a mudança na sistemática de remuneração por tarefa, 600 operárias da fábrica de tecidos Sant' Anna, pertencente a Antonio Álvares Penteado, entraram em greve. As grevistas foram apoiadas por anarquistas (Fanfulla, Tribuna Italiana) e socialistas (Avanti). Obtiveram, ademais, o apoio da Liga de Resistência dos Trabalhadores em Madeira, dos Operários de Artes Gráficas e Anexas, e de algumas categorias de trabalhadores de São Roque. ${ }^{17}$ Ainda em 1901, um movimento grevista de trabalhadores de pedreira conseguiu a redução da jornada de trabalho de 12 para 10 horas. Outras greves reivindicavam a pontualidade no pagamento salarial e embora malsucedidas deram ensejo ao Segundo Congresso Socialista Brasileiro, reunido em maio de 1902, na capital paulista, de anunciar a generalização de ofensivas operárias à opressão capitalista ${ }^{18}$.

O mês de março de 1902 assinalou a greve dos operários da fábrica de chapéus Deodato Leme, pelo pagamento salarial no princípio de cada mês. Os grevistas tiveram o apoio dos anarquistas, com cobertura dada pelo periódico O Amigo do Povo, dirigido por Neno Vasco. O Núcleo Filodramático Libertário realizou um espetáculo em benefício dos grevistas, que receberam a solidariedade da Liga de Resistência dos Sapateiros, além de 748\$113, arrecadados da caixa da Liga de Resistência da categoria e de uma coleta procedida entre chapeleiros das demais fábricas. Essa solidariedade não se manteve, pois dois meses mais tarde o movimento malogrou pela traição à causa comum de uns "pochi krumiri” (fura-greves) ${ }^{19}$.

Em outubro de 1902, as tecelãs da Fábrica de Tecidos Anhaia, no Bom Retiro, levantaram-se contra os maus tratos infligidos pelo mestre de teares a Emma Sartorelli, de 17 anos de idade, que acabou por ser demitida sumariamente ${ }^{20}$. Os anarquistas solidarizaram-se com as grevistas, promovendo um festival "pro sciopero", organizado pela Liga de Resistência entre Tecelões e Tecedeiras de São Paulo ${ }^{21}$.

Em 1903, o anarquista espanhol Everardo Dias fundou o jornal O Livre Pensador. Nesse ano, os tecelões de São Paulo entraram em greve pela redução da jornada de trabalho, que era 
de 14 a 15 horas. Ainda no mesmo ano, no mês de setembro, foi fundado em São José do Rio Pardo o "Clube Internacional Filhos do Trabalho", socialista, do qual fazia parte Euclides da Cunha $^{22}$.

No ano de 1904, os operários de São Paulo comemoraram, pela primeira vez no Brasil, o “ 1. ' de Maio". Nessa data, O Estado de S. Paulo publicou um artigo de Euclides da Cunha no qual se lê que fora com Karl Marx que o socialismo científico começara a usar uma linguagem firme, compreensível e positiva, e que o capitalismo colocou o trabalhador num nível inferior ao da máquina. $\mathrm{O}$ artigo conclui pela justificação do duplo princípio fundamental defendido pelos socialistas: socialização dos meios de produção e circulação; posse individual somente dos objetos de uso.

A fim de melhor defender as reivindicações operárias, Oreste Ristori fundou em 1904 o semanário anarquista La Bataglia. ${ }^{23}$

Movimento mais amplo ocorreu em junho de 1905, partindo dos estivadores do Porto de Santos e se estendendo a carroceiros, operários de pedreiras, engraxates, marchantes, barbeiros e até padeiros. A intervenção policial nesse movimento, requerida pela Associação Comercial de Santos, acirrou a repressão, reduzindo os líderes grevistas à condição de delinquentes comuns.

Em maio e junho de 1907, os operários da cidade de São Paulo realizaram uma grande demonstração de força pela jornada de oito horas, atendendo à recomendação do Primeiro Congresso Operário Brasileiro, realizado no ano anterior. Em 12 de maio de 1907, os industriais de São Paulo, sob a presidência do conde Álvares Penteado, decidiram que "as oito horas de trabalho reclamadas com tanta insistência não devem ser concedidas, pois contribuirão para que os operários, ainda mais que hoje, empreguem seus lazeres nos botequins e festanças, onde pervertem o espírito, dando trabalho à polícia." 24

As greves gerais de 1907 ocorridas em São Paulo, Rio de Janeiro e interior foram duramente reprimidas. Patrões e polícia atribuíram os movimentos grevistas a agitadores profissionais, pagos por governos estrangeiros para matar a industrialização nascente do Brasil. No mesmo ano foi promulgada a Lei Adolpho Gordo - a "Lei Celerada" -, que autorizava a expulsão de líderes operários estrangeiros e o internamento dos brasileiros que comprometessem a "segurança nacional". No seu primeiro ano de vigência, a Lei Celerada expulsou 152 líderes operários estrangeiros; nos anos seguintes, outras centenas foram banidas do Brasil. Logo depois foi promulgado o Decreto 1.637, que passou a exigir que os dirigentes sindicais operários fossem brasileiros natos ou naturalizados. 
Em setembro de 1909, os operários da Vidraria Santa Marina deflagraram greve por aumento de salário para os menores, que trabalhavam como portadores de garrafas. $\mathrm{O}$ gerente chamou a polícia; em represália, a greve estendeu-se a toda a fábrica. Os operários organizaram uma comissão para representá-los, comissão que exigiu a demissão do gerente. A direção da fábrica concordou com o aumento salarial das crianças, mas se recusou a demitir o gerente, ameaçando com lock-out caso o trabalho não fosse reiniciado. Nesse sentido, o forno a mão foi apagado, com a dispensa dos que nele trabalhavam, os quais foram intimados a abandonar as casas que habitavam, pertencentes à fábrica, num prazo de oito dias. Os operários dos fornos a máquina foram ameaçados com a mesma sanção. ${ }^{25}$

Nesse ambiente de luta desigual, grupos crescentes de operários ingressavam nos sindicatos e militavam em grupos anarquistas, anarco-sindicalistas, socialistas e mesmo comunistas, embora estes últimos fossem ainda incipientes no cenário brasileiro.

As tentativas de associação dos operários eram constantemente ameaçadas, com invasões de recintos nos quais se faziam reuniões preparatórias de movimentos reivindicatórios, com prisões e com dispensas de emprego de lideranças trabalhistas. Nesse sentido, a demissão de dois empregados da Light, motivada pelo fato de terem sido eles os chefes e organizadores da União Defensora dos Empregados da Light, provocou uma "parede" de seus colegas, abortada pela prisão de diversos motorneiros, acusados de serem os principais chefes do movimento. ${ }^{26}$

\section{Lideranças operárias}

As primeiras lideranças operárias costumavam ser formadas por "tipos bizarros e fascinantes" ${ }^{27}$, que ficaram na memória operária como pessoas que viviam o único ódio à má organização social; no mais, passavam "a sua pobreza discreta, quase oculta, sem uma queixa, sem uma leve demonstração de arrependimento, sem o menor desalento, sem manifestar tristeza ou mau humor" ${ }^{28}$. Líderes dessa natureza, reunidos nos grupos anarquistas do La Bataglia e do Lanterna, orientaram, juntamente com a Liga dos Pedreiros, amplo movimento de pedreiros e categorias anexas de São Paulo, no ano de 1911. Aderiram ao movimento 10.000 operários, sem que se contasse uma única traição. A mobilização estendeu-se a Campinas, Jaú e Sorocaba. ${ }^{29}$ A repressão, ainda uma vez, sufocou a greve, prendendo várias dezenas de operários e os redatores do La Bataglia e do Lanterna, vistos como os fomentadores do movimento. ${ }^{30}$ No mesmo ano, criou-se em São Paulo o Departamento Estadual do Trabalho, para cuidar da "questão social" que, segundo os políticos, não existia. 
Edgard Leuenroth, diretor-proprietário do Lanterna ${ }^{31}$ e do A Plebe $e^{32}$, em 1912, planejou um movimento subversivo na capital paulista, de acordo com a Federação Operária do Distrito Federal, também anarquista. ${ }^{33}$ Concomitantemente, os anarquistas organizaram no Brás as "Escolas Libertárias Livres", que deveriam cooptar o proletariado paulista para a causa revolucionária.

A legislação repressiva continuou a se radicalizar, tangida pelo temor dos empresários diante da agitação proletária. As atenuantes do Decreto n. ${ }^{\circ}$ 1.641, de 7/1/1907, que punia com a expulsão o estrangeiro que, por qualquer motivo, comprometesse a segurança nacional ou a tranquilidade pública, foram revogadas pelo Decreto n. ${ }^{\circ} 2.741$, de 8/1/1913, promulgado por Hermes da Fonseca. Dezenas de anarquistas passaram a ser caçados em São Paulo e, uma vez presos, deportados do Brasil, no prazo de 15 dias.

Neste impasse, os operários se mobilizaram em torno da Confederação Operária Brasileira, decidindo-se pela realização de comícios nos diversos centros urbanos, contra a carestia, o salário baixo e a excessiva jornada de trabalho. ${ }^{34}$ Como os comícios estivessem proibidos pela polícia, as lideranças operárias paulistas optaram por promover reuniões em diversos bairros da capital, para depois convergir todos os trabalhadores ao Largo São Francisco, para um comício de protesto. ${ }^{35}$

A crise de 1914 abateu-se pesadamente sobre os proletários paulistas, que se defrontaram, pela primeira vez, com o desemprego em massa. Em agosto, já configurado o estado de calamidade pública, a imprensa da capital patrocinou um Comitê de Assistência em benefício das famílias desempregadas. ${ }^{36} \mathrm{D}$. Miguel Kruse, um dos organizadores do comitê, declarou que por causa das desordens e acúmulo de pessoas no Largo de S. Bento, o Mosteiro resolvera não mais distribuir gêneros e dinheiro aos necessitados que procuravam diariamente a instituição. ${ }^{37}$ Calculava-se, nessa ocasião, a existência para mais de 10.000 operários sem trabalho na cidade de São Paulo. Como era previsível, as comemorações do 1. ${ }^{\circ}$ de Maio de 1914 foram marcadas por violentos protestos das associações operárias contra o aumento do custo de vida e o brutal desemprego. ${ }^{38}$

\section{O impacto da Revolução Russa nos meios revolucionários brasileiros}

Em 1917, o movimento operário sofreu dois fortes impactos: a entrada do Brasil na guerra e a Revolução Russa.

Em finais de outubro, as notícias sobre a Revolução Russa chegaram ao Brasil, provocando grande entusiasmo nos meios operários, fato que levou a polícia a afirmar que, 
grosso modo, a primeira manifestação concreta de propaganda comunista no Estado de São Paulo verificara-se com a greve geral de novembro de 1917, na Capital. A esse tempo, o movimento operário se enfeixava quase todo nas mãos dos anarquistas e anarco-sindicalistas, dispersos pelas associações de classe e sociedades operárias ou agrupados em torno da Federação Operária do Estado de São Paulo.

Terminada a guerra, ressurgiram as lutas operárias. Já nas comemorações do Primeiro de Maio de 1919, no comício da Praça da Sé, uma multidão de trabalhadores aplaudiu vivamente Manuel Campos, delegado do Partido Comunista do Brasil, bem como Florentino de Carvalho, Hélio Nigro e Edgard Leuenroth, o último a discursar e o mais ovacionado. O comício terminou com A Internacional e com uma marcha dos participantes pelas ruas paulistanas, com uma comissão de frente formada por moças vestidas com blusas vermelhas. ${ }^{39}$

No dia seguinte a essa manifestação irrompeu um movimento grevista que se generalizou, atingindo cerca de 50.000 operários e se estendendo a outras cidades paulistas.

Após 1919 o número de greves diminuiu, mas os operários paulistanos continuaram a se agitar e a se organizar, especialmente nos sindicatos. Azis Simão arrola 246 movimentos de paralisação do trabalho ocorridos em todo o Estado, de 1901 a $1930 .^{40}$ As greves desse período marcaram-se por duas tendências nítidas: as greves por motivo de número de horas de trabalho concentraram-se entre 1906 e 1915 (88,9\%), e as referentes a questões salariais entre 1911 e $1920(69,6 \%)$. Para as três décadas iniciais do século passado, 57,4\% das greves foram motivadas por questões salariais e $34,5 \%$, por más condições de trabalho. As soluções dadas aos movimentos mais expressivos ocorridos na capital em 1917 e 1919 ocasionaram possivelmente a sensível queda de greves a partir de $1920 .{ }^{41}$ Este ano registrou uma única greve interprofissional e, até 1937, os conflitos de trabalho limitaram-se a estabelecimentos ou setores econômicos específicos. A partir de 1923 decresceram mesmo as ocorrências setorizadas, existindo anos que não registraram nenhuma agitação operária na capital ou no interior. Foster Dulles, simplificando tabela elaborada por Azis Simão, elabora uma tabela minuciosa sobre as ocorrências de greve no período de 1917-1935. ${ }^{42}$

A Plebe denuncia que crianças de nove e dez anos eram obrigadas a trabalhar por tarefa, sendo depois prejudicadas no peso do material utilizado e, ainda por cima, multadas por se rirem ou por irem beber água. ${ }^{43}$ Por sua vez, as mocinhas eram as preferidas pela indústria têxtil, que só empregada homens como contramestres, mestres e tecelões especializados. Aos gerentes e diretores só se podia falar de chapéu sobre o peito, fazendo vênia de beija-mão, numa humildade de escravos. 
A colaboração da polícia paulista com os industriais é comprovada a cada passo pelos arquivos policiais. Os industriais utilizavam-se cinicamente de argumentos ligados à situação de penúria de seus empregados para requerer a intervenção policial nas greves operárias, como fazem "diversos industriais de calçados" em carta "confidencial" ao delegado de Ordem Política e Social, aconselhando medidas radicais contra os grevistas. ${ }^{44}$

Para atender a apelos dessa natureza, a polícia mantinha informes pormenorizados sobre os trabalhadores, colocando-se ostensivamente a serviço dos industriais. Nos registros do DEOPS/SP abundam listas de "elementos reconhecidamente comunistas e agitadores" 45.

Assim, a década de 1920 fortaleceu o proselitismo exercido pelos líderes proletários ao fornecer-lhes a teoria e a prática marxistas do Partido Comunista Brasileiro, que se transformou no maior aglutinador da massa popular, tendo em vista a revolução social. De 1922 a 1930, a história do partido divide-se em três fases: a primeira, de 1922-25, marca a sua aparição; a segunda, de 1925-1927, corresponde à consolidação da nova situação; a terceira, de 1927-30, define-se pela ampla agitação de massa. Nesta última, o partido envolveu-se em frentes políticas e sindicais, com o objetivo de atingir camadas sociais situadas fora do círculo estreito em que vivia. Foi a hora da organização do Bloco Operário e Camponês, do jornal A Nação, do Congresso Sindical e da Confederação Geral do Trabalho. ${ }^{46}$ Hora, igualmente, das primeiras dissensões nos quadros do PCB.

A primeira fase assistiu à fundação da seção paulista do PCB, ocorrida no ano de 1923, por meia dúzia de pessoas, sob a presidência de Astrojildo Pereira. ${ }^{47}$ Desde então os meios revolucionários paulistanos dividiram-se entre adeptos e adversários da Revolução Russa, que aparecia como o grande exemplo histórico de uma sociedade sem classes. Não obstante, durante algum tempo, mesmo entre adeptos, o exemplo bolchevista apresentou-se carregado de ambiguidades, das quais resultaram em parte as posteriores dissensões no movimento operário.

Mal instalado o comitê regional paulista do PCB, o jornal anarquista A Plebe saudou as ideias do comunismo anarquista e os modernos princípios da liberdade, denotando que tal acontecimento aparecia nebuloso aos olhos da esquerda paulista. Os anarquistas de São Paulo sustentaram uma atitude de simpatia para com a Internacional Sindical Vermelha, reconhecendo a sua obra de preparação revolucionária, mas criticando a sua subordinação à Terceira Internacional.

No mesmo ano da fundação da seccional paulista do partido, São Paulo viveu a greve dos gráficos, movimento que revelou as qualidades de João da Costa Pimenta, o secretário-geral da União dos Trabalhadores Gráficos de São Paulo (fundada em 1919), e um dos melhores 
organizadores trabalhistas de seu tempo. No dia 24 de março, a imprensa proletária (A Plebe, $O$ Trabalhador Graphico e O Internacional) saudou a vitória completa desse movimento ${ }^{48}$.

A interpretação burguesa sobre as greves do período baseou-se fortemente no fato de ser a maior parte dos trabalhadores categorizados formada por estrangeiros. Assim robusteceu-se a ideia muito difundida no Brasil dos anos de 1920 a 1940 que atribuía a estrangeiros a responsabilidade pela subversão da ordem social. O Quarto Recenseamento Nacional registra que, em 1920, São Paulo era a segunda maior cidade brasileira, com meio milhão de habitantes, a maioria formada por imigrantes e seus descendentes. Essa "cidade carcamana" converteu-se no centro intelectual mais criativo do Brasil, servido por uma imprensa alternativa valente, e por uma indústria gráfica capaz de produzir livros da melhor qualidade. A presença numerosa de imigrantes e seus descendentes em São Paulo fazia com que explicações padronizadas, tributárias da equação bolchevismo com influência estrangeira, fossem amplamente aceitas pela opinião pública. A existência de um contingente ponderável de imigrantes nas fileiras operárias concede peculiaridade à história da esquerda na capital paulista, explicando muitos de seus caminhos. Os imigrantes trouxeram a experiência que possuíam de participação em organizações operárias, editando jornais em idiomas estrangeiros, principalmente italiano e espanhol, e contribuindo para inculcar a consciência de classe no operário brasileiro. ${ }^{49}$

Além do vasto número de imigrantes estrangeiros, outras especificidades paulistanas originaram-se do grau maior de desenvolvimento capitalista, responsável pela incorporação da pequena burguesia ao sistema de alianças da classe dominante, dificultando mediações e polarizando conflitos, além de impedir a formação de uma pequena burguesia e de mobilizações nacional-populares. ${ }^{50}$ Entretanto, as condições materiais de existência foram determinantes para a difusão de ideias revolucionárias para todo o Brasil, embora os esforços desenvolvidos por líderes proletários não conseguissem jamais fazer dos partidos de esquerda partidos de massa. ${ }^{51}$

Com a eclosão da crise denominada "questão militar" na presidência Bernardes, o partido se fortaleceu na capital paulista, valendo-se dos conflitos armados provocados pela Revolução de 1924. Os motins populares, as arruaças e os saques dirigidos contra armazéns e depósitos de víveres foram identificados pela polícia como novos esforços de propaganda dos comunistas: "Os que ocultamente dirigiram tais agitações, conduziam as massas pregando-lhes a necessidade de dividir a fortuna dos ricos com os pobres." 52 


\section{O Comitê Regional do Partido Comunista do Brasil em São Paulo}

Em 1925, procurando enfrentar a falta de interesse geral pelo PCB em São Paulo, a CCE (Comissão Central Executiva) colocou o gráfico Mário Grazini e o jornalista Aristides Lobo na liderança da seção regional paulista, no lugar de João da Costa Pimenta, iniciativa que Octavio Brandão considera inútil, pois o partido teria continuado no mesmo marasmo. Opinião diversa apresenta-se em relatório da Superintendência da Ordem Social sobre o PCB, ao registrar resultados positivos da atuação desses líderes ${ }^{53}$. Segundo a polícia, foi nessa época que a Internacional Comunista demonstrara uma preocupação efetiva pela intensificação e pela coordenação do trabalho revolucionário, isto é, pela preparação das grandes massas para o advento do regime marxista, instalando nas capitais platinas o "Secretariado Latino-Americano" ou "Bureau Político Latino-Americano", sede que se transferira para o Rio de Janeiro.

De 1923 a 1928, os comunistas que militavam na capital paulista associavam-se a líderes pertencentes a outras correntes da esquerda - em especial anarquistas e socialistas —, para manifestações coletivas diversas. O sectarismo ainda não havia marcado os combates operários, dividindo de forma tão profunda os protagonistas da revolução proletária. Assim, a documentação da época apresenta conjuntamente comunistas, anarquistas e fascistas nas comemorações de $10^{\circ}$ de Maio, nas conferências e nos comícios. As relações de amizade então estabelecidas entre muitas personagens da esquerda paulista, aparentemente resistiram aos progroms stalinistas, explicando em parte a ocorrência de frentes únicas na década de 1930.

Embora incontestavelmente sob a influência de teóricos e partidos europeus, cada corrente de esquerda era prisioneira da história brasileira, da história de São Paulo e, em última instância, das relações pessoais estabelecidas entre seus quadros. Desse ponto de vista, as interações do PCB com o ambiente nacional, estudadas como predeterminações para muitas atividades e posições dos comunistas - juntamente com as convergências entre o partidarismo soviético - devem ser acrescidas com os laços de amizade, sempre fundamentais em nossa história.

É preciso notar que a seção paulista do PCB apresentou pouco desenvolvimento nos primórdios de sua história. Por esse motivo, em maio de 1927, em pleno movimento do BOC (Bloco Operário Camponês), elementos comunistas reuniram-se para fundar um novo CRSP (Comitê Regional de São Paulo), no qual Everardo Dias ocupou a secretaria-geral; um operário, a secretaria de organização; outro operário foi escolhido para secretário sindical; Plínio Melo figurou como primeiro-secretário; e Aristides Lobo, como secretário do Agitprop. Em 1928 estavam organizadas células nos bairros da Luz, Brás, Mooca, Santa Efigênia, e mais duas no 
Centro e Bom Retiro. A ordem do dia da Conferência de Agitprops compreendia agitação nas fábricas, propaganda individual, difusão de literatura, expansão do A Classe Operária, BOC, seção operária de $O$ Combate, cursos, jornais sindicais, trabalho ilegal. ${ }^{54}$

Um informe reservado reitera essa posição da liga, denunciando que Plínio Mello havia redigido um manifesto de crítica à Lei de Sindicalização, distribuído por ele e João Matheus na Federação Operária. Na ocasião, o elemento de confiança da polícia, Arsênio Palácios, dissera que a UTG (União dos Trabalhadores Gráficos), com a entrada dos elementos que faziam parte do PC e da liga, transformara-se numa sucursal direta de Moscou e que, por isso, solicitava que o plenário suspendesse os delegados da UTG junto à Federação Operária. Essas declarações provocaram "balbúrdia" e o plenário foi encerrado. ${ }^{55}$

Durante a realização da $3 .{ }^{a}$ Conferência Operária, em 16/3/31, convocada e patrocinada pela Federação Operária de São Paulo, a União dos Trabalhadores da Ligth pede para ser lida uma moção protestando contra a opressão exercida pelo capitalismo, não só contra os trabalhadores russos, mas também contra os trabalhadores do resto do mundo. Aristides Lobo responde que na URSS não se perseguiam trabalhadores, mas um ou outro militante político. A respeito, leu um protesto que os comunistas dissidentes iriam enviar a Stálin, contra a perseguição de que eram vítimas na Rússia os comunistas pertencentes à fração leninista, como Rakoviski e outros membros da ala leninista-trotskista. A moção de protesto é aprovada, estendendo-se a uma delegação operária do interior, que esteve presa por cinco dias na capital paulista, e a Florêncio Tejeda, que se encontrava preso, com ameaças de deportação. ${ }^{56}$

Atitudes solidárias aos revolucionários estiveram presentes até em esferas policiais, tendo em vista relações pessoais ou profissionais preexistentes entre os prisioneiros e os seus guardas. É o que podemos observar em numerosos documentos da repressão. Como exemplo, citamos uma carta de Antônio Ghioffi, um secreta da polícia que atuava nos meios sindicais, datada de 29/4/31, advertindo o delegado da Ordem Política e Social de possíveis infiltrações de comunistas no Gabinete de Investigações, propiciadas pela "ingenuidade" do Dr. Raphael Corrêa de Oliveira, com a intimidade que mantinha com pessoas que chefiavam o movimento revolucionário em São Paulo. ${ }^{57}$ Em confirmação, Ghioffi informa, alguns dias mais tarde, que Coripheu de Azevedo Marques estava a par das prisões que seriam efetuadas, das quais soubera por intermédio de Jayme Adour da Câmara, que copiara os nomes de 12 indivíduos a ser presos, de uma pessoa do Gabinete de Investigações. Ademais, Azevedo Marques esteve à procura de Raphael Corrêa de Oliveira para tratar da liberdade de João da Costa Pimenta. De igual modo, quando um inspetor da DOPS procurara Aristides Lobo em sua residência, pretextando fazer- 
The a entrega de uma carta vinda do Rio, Aristides já estava preparado para o caso, "em vista do que fracassou a diligência" 58 .

\section{Ação sindical e luta para a união do proletariado}

Os opositores de esquerda em São Paulo atuavam especialmente nos sindicatos, aos quais todos se deveriam filiar, por princípio. Nessa área, travavam-se as principais lutas das correntes de esquerda pelo controle da massa trabalhadora. A primeira crítica feita pelos opositores à burocracia dirigente do PCB dizia respeito ao "tradicional horror" que a mesma tinha ao trabalho sindical, vendo nisso "uma monstruosidade". E, pretendendo explicar o "desleixo" que decorria diretamente de sua incapacidade nessa questão, alegava que os sindicatos operários de São Paulo eram organizações "fascistas". 59

$\mathrm{Na}$ óptica dos oposicionistas de esquerda, a organização dos trabalhadores brasileiros tinha sido boicotada pelo partido que conseguiu, após 1930, que as massas recaíssem no desinteresse político habitual e o governo provisório se consolidasse.

A OE (Oposição de Esquerda) dividia o movimento sindical no Brasil em duas fases principais, separadas pelas grandes greves de 1917-19, caracterizadas pela dispersão, fraqueza orgânica e sectarismo. Na primeira fase, o movimento sindical se desenvolveu sob a influência direta do anarco-sindicalismo e, em grau menor, sob a inspiração de elementos reformistas. A segunda fase foi assinalada pela influência ascendente dos comunistas nos movimentos grevistas. Quanto aos congressos operários, o primeiro deles (1906) marcou grandes progressos na organização dos trabalhadores, porém a vaga de greves de 1917-19 foi derrotada, o que se deveu à inexistência de um verdadeiro partido proletário à frente do movimento operário. $\mathrm{O}$ segundo congresso realizou-se em 1919, logo seguido pelo terceiro congresso, um ano depois. Este último denunciou o caráter negativista dos princípios anarquistas até então dominantes no movimento sindical brasileiro. A falta de tradições marxistas no movimento operário do país e o fato de os fundadores do PC serem quase todos de origem anarquista contribuíram para que o partido não pudesse realizar uma política sindical que se ajustasse ao seu programa. $\mathrm{O}$ Congresso Operário de 1929, que, historicamente, podia ser considerado como o $4 .^{\circ}$ Congresso Sindical Brasileiro, organizou a Confederação Geral do Trabalho, que, no entanto, não conseguiu a centralização da grande maioria dos sindicatos. Reproduzia-se na liderança comunista do movimento sindical, o que já acontecera antes, sob a direção dos anarquistas. A confusão das ideias de sindicato e partido determinou, em grande parte, a liquidação não só da CGT como da maioria dos sindicatos mecanicamente controlados pelo PC. Generalizou-se no 
partido a ideia de que cada sindicato deveria se tornar apêndice do Partido, transformando-se em foco de agitação comunista. ${ }^{60}$

Os movimentos operários no Estado de São Paulo, após o marasmo de 1923-27, recrudesceram, acalentando as esperanças das lideranças revolucionárias numa comoção maior. O centro da luta era, necessariamente, a cidade de São Paulo, que aglutinava as principais lideranças operárias do Estado e mesmo do país. Nessa cidade, o sindicato mais importante era a União dos Trabalhadores Gráficos. Em 21 de maio de 1931, em reunião nesse sindicato, discutiu-se sobre o desligamento da UTG da Federação Operária. ${ }^{61}$

De outro lado, a política corporativista de Vargas significava a interferência oficial do Ministério do Trabalho na organização do proletariado, trazendo o perigo do colaboracionismo e divisão do proletariado pela classe inimiga. ${ }^{62}$ Nessa ocasião, o movimento sindical apresentava as seguintes formas: 1. sindicatos criados pelo Ministério do Trabalho (oficializados); 2. sindicatos colaboracionistas (reformistas, amarelos, organizações católicas, uniões mutualistas e beneficentes, etc.); 3. sindicatos de luta de classe (ação direta). A corrente anarco-sindical era antiestatal, antiautoritária e apolítica. Suas organizações tinham um caráter tipicamente sindicalista. Não se apoiavam em partidos políticos, mesmo que fossem partidos operários, nem aceitavam qualquer orientação partidária. A sindical-reformista aceitava a colaboração dos poderes públicos, a arbitragem do Estado, e estava cooptada pelo Ministério do Trabalho. A corrente comunista, partidária da ação direta, atuava mediante o uso de métodos revolucionários, visando à destruição do regime, a fim de implantar a ditadura proletária e cooptar os trabalhadores para a luta de classes. ${ }^{63}$

Ao contrário do que entendem alguns historiadores, a influência anarquista no sindicalismo paulista ainda era dominante em 1931, uma vez que, após a crise de 1930, acompanhada por prisões e extradições de libertários, o anarquismo passava por um renascimento propiciado pela agitação contra o ensino religioso. ${ }^{64}$ Em 1934, os anarquistas promoviam conferências em São Paulo, na capital e em Santos, mantinham o Centro de Cultura Social e organizavam festivais e piqueniques no Parque Jabaquara. ${ }^{65}$

O anarco-sindicalismo dominava a Federação Operária e mantinha uma congênere, a Federação Comunista Libertária, que tinha por fins imediatos o estudo e a propagação de doutrinas que pregassem a igualdade de condições econômicas e sociais de todos os seres humanos, a eliminação completa do Estado, e a reorganização da vida social sob o regime da ordem, da justiça e da liberdade. ${ }^{66}$ Princípios que não diferiam em essência daqueles apregoados pelos comunistas e que se apoiavam numa imprensa potente e em líderes 
respeitados pela classe trabalhadora. Edgard Leuenroth, evidentemente, dominava a cena, acompanhado por companheiros de luta, muitos dos quais, ainda em 1948, conservavam "um diminuto prestígio da massa" e continuavam a editar os jornais A Plebe e A Lanterna. ${ }^{67}$ Reunidos principalmente na "União Anarquista" (também chamada de "Centro de Cultura Social"), os anarquistas de São Paulo estavam envolvidos na questão referente aos revisionistas do anarquismo libertário, considerados como responsáveis por um recuo ao autoritarismo. A argumentação fundamental versava sobre a tão debatida questão de um programa anárquico, apto para tomar as rédeas à revolução — de manejar as massas para decidi-las pela ordem social baseada no comunismo anárquico. Os revisionistas pretendiam um governo anárquico, de caráter transitório. Para os anarquistas históricos, tanto valia que os revisionistas se passassem diretamente para o campo dos comunistas de estado. O comunismo autoritário era por eles visto como uma "ditadura pseudoproletária, dotada de uma centralização mastodôntica e significando sobretudo governo, monopólio, liberticídio, asfixia e opressão do indivíduo". O comunismo anárquico afirmava sua razão de ser na não-predominância de classe, no não-governo, na livre associação, na livre iniciativa, em núcleos autônomos e na liberdade integral do indivíduo. ${ }^{68}$

A luta contra os comunistas foi constante na história dos anarco-sindicalistas de São Paulo. Em 1931, a Federação Operária de São protestou contra a sabotagem das notícias que eram enviadas ao $O$ Tempo, com o fim de que saíssem publicadas unicamente aquelas que se referiam à Confederação Geral do Trabalho, organização comunista que respondia ao seu respectivo partido. ${ }^{69} \mathrm{Na}$ Federação Operária de São Paulo, entre muitos, atuava José Carlos Boscolo, diretor da UTG. Preso após a Intentona, declarou que colaborava nos jornais A Plebe e A Lanterna, escrevendo sobre assuntos sindicais, sociais e anticlericais. ${ }^{70}$

Em todos os acontecimentos operários, apesar do pequeno número de aderentes, a Liga Comunista fazia-se presente, como demonstra o meticuloso serviço de informes reservados da Delegacia de Ordem Social. Por esses documentos, seguimos a atuação da LC para tentar se impor na conferência da Federação Operária de São Paulo, quando seria discutido o sindicalismo revolucionário. O partido se preparou para criticar a ação da federação. Segundo o informante policial, "presentemente os comunistas tratam de orientar-se por meio de Afonso Schmidt e Aristides Lobo, depois de terem angariado várias assinaturas para o caso WICKOSU, para que o mesmo seja readmitido no partido, e, com ele, todos, ou a maioria dos que foram expulsos". O Manifesto Comunista (Marx é entendido como "Marques") merece o seguinte relato do secreta: 
O mesmo grupo estava trabalhando para a publicação de um manifesto, estando encarregada dos preços a Tipografia Mário Dupont, ex-Jovem Comunista, que em outros tempos trabalhou para a formação da Juventude Comunista. O manifesto trará a assinatura de Marques ou outro qualquer. Aristides recomendou que se obtenha o preço mínimo, contra pagamento imediato por mil exemplares. ${ }^{71}$

O Congresso Operário, ao qual se referia Ghioffi, constituiu o ponto culminante da atividade da LC, do qual participou sem o partido. No Congresso Operário, a LC constituiu uma pequena fração que, pela primeira vez, defendeu pública e abertamente a linha sindical comunista, aparecendo como organização política, fração de esquerda do partido. A ata da "Sessão Pública de Encerramento da 3. ${ }^{a}$ Conferência Operária de São Paulo", realizada nos dias 13, 14, 15 e 16 de março de 1931, permite-nos ter uma ideia sobre o operariado paulista, ao mesmo tempo em que podemos ver os aderentes da liga em plena ação junto a correntes majoritárias que lhes eram hostis, numa tática que procurava contrabalançar o pequeno número de aderentes com a demonstração de uma imensa combatividade. No decorrer do ano de 1931, a Confederação Geral do Trabalho do Brasil e a Federação Sindical Regional convocaram três congressos de unidade sindical, mas todos fracassaram. O primeiro, realizado em março, teria sido convocado especialmente para desmoralizar o Congresso promovido pela Federação Operária de São Paulo. Este se realizara, porém, nos dias 13, 14, 15 e 16 e os comunistas (aderentes da liga, como vimos) propuseram ao plenário do Congresso da Federação Operária a frente única, que foi rejeitada por todas as organizações, com exceção dos votos da delegação dos gráficos. A Federação Sindical Regional de Santos estava também em mãos do partido. ${ }^{72}$

Nesse ano de 1931, a União dos Trabalhadores Gráficos, considerando-se como a vanguarda proletária paulista, apresentou uma proposta de desligamento da UTG da Federação Operária de São Paulo, em virtude da prisão de diversos militantes gráficos e a outras ocorrências, diante das quais a atitude da direção daquele organismo proletário foi vista como dúbia e equívoca. Na mesma ocasião, revelando a influência trotskista de seus quadros de liderança, a UTG manifestou-se favorável à proposta de frente única feita pela Federação Sindical Regional de São Paulo. ${ }^{73} \mathrm{O}$ afastamento dos gráficos da federação justificava-se plenamente: além das tendências anarquistas, aquela organização estava - no momento dominada por Hermínio Marcos, colaborador da polícia. Nessa qualidade, ele lançara um boletim todo consagrado ao combate aos elementos comunistas da federação, especialmente os trotskistas. Motivo pelo qual "fatalmente os comunistas leninistas virão atacar com mais denodo os elementos da Federação", diz Ghioffi. ${ }^{74}$ 
Os stalinistas concentraram seus esforços no terreno sindical no objetivo de unir todos os sindicatos em torno de uma única confederação, por eles dirigida. No Rio, o movimento data de $1927^{75}$; em São Paulo, de 1931, com um atraso que deixa perceber a grande influência ainda exercida pelos anarco-sindicalistas e pelos trotskistas. ${ }^{76}$

A Federação Operária de São Paulo diante da atitude política (oposição com maior intensidade e burocracia com menor) que vinha tomando a UTG, expulsou-a do seu seio, ficando, por isso, os trotskistas quase sem ação no meio operário, reduzindo-se as suas atividades ao campo gráfico. Caso viesse a triunfar a tese de Aristides Lobo, o partido e a liga fariam um acordo no terreno sindical; depois procurariam a adesão da Federação Operária. Esta organização era liderada por Arsênio Palácios, um dos temidos "agentes reservados" infiltrados no meio sindical, que recebe este elogio da polícia: a FO muito devia a esse brasileiro, filho de espanhóis, poeta e jornalista, pela maneira inteligente como a dirigia. ${ }^{77}$ Cópia de uma notícia da Folha da Manhã, datada de 3/8/31, reproduz esse juízo de valor sobre Palácios, testemunhando que muitas notícias de jornais eram produzidas direta ou indiretamente por policiais. Diz a notícia que São Paulo possuía 13 sindicatos com aproximadamente 1.000 trabalhadores filiados à FO, graças "à ação enérgica de Hermínio Fernandes, Arsênio Palácios, Francisco Cianci e outros". Apesar da situação da FO, a liga considerava que o combate contra os anarcosindicalistas e, em última instância, a luta de classes, impunham a formação de uma frente única sindical. Além do documento de Aristides Lobo, há um outro defendendo a mesma tese, de autoria de "Tapejara", isto é, Plínio Melo, que usava esse mesmo pseudônimo para escrever no jornal $O$ Trabalho e nas publicações da LC. ${ }^{78}$

O setor "Agit-prop" (agitação e propaganda) da liga publicou nesse período dois números do Boletim da Oposição, um contendo um manifesto em favor da organização sindical e outro a favor de uma Assembleia Constituinte. Ainda foram publicados os números 6 e 7 de A Luta de Classe e um folheto de divulgação popular das idéias da oposição: "A Oposição Comunista e as calúnias da burocracia" . Nessa época também foi iniciado um trabalho cultural, com um programa de edições marxistas, que resultou nas seguintes publicações: $O$ marxismo e No caminho da Insurreição, ambos de Lenin, O Manifesto Comunista e Os princípios do comunismo, de Marx e Engels. ${ }^{79}$

\section{Associação de Amigos da Rússia e Socorro Proletário}

Em 31 de março de 1931, a propaganda intelectual em favor da URSS aumentou, ao surgir em São Paulo a "Associação dos Amigos da Rússia", cuja missão principal era a difusão 
do conhecimento do marxismo revolucionário, embora para o público externo assumisse a feição de incentivar o intercâmbio comercial, intelectual e artístico com a URSS. ${ }^{80}$ Foi fundada por um grupo de intelectuais comunistas, da Oposição de Esquerda, para forçar o governo a reconhecer a Rússia e manter um intercâmbio com aquele país. ${ }^{81}$ Essa iniciativa ligava-se à posição que a liga defendia de defesa da URSS, como a pátria dos proletários, ao mesmo tempo em que atacava o stalinismo, como traidor da causa revolucionária marxista-leninista.

Uma relação de sócios da AAR inclui aderentes e simpatizantes da liga, na relação de 158 nomes, em geral composta por intelectuais socialistas e oposicionistas de esquerda, embora também figurem simpatizantes do partido. Nesse elenco, podem ser lidos os nomes de Euclides da Cunha, Emiliano Di Cavalcanti, Flávio de Carvalho, Genolino Amado, Oduvaldo Viana, Oswald de Andrade. ${ }^{82}$ A presença exclusiva de intelectuais nos quadros da associação justificava-se pelo artigo 1. ${ }^{\circ}$ de seus estatutos: destinava-se a intensificar as relações intelectuais do Brasil com a União das Repúblicas Socialistas Soviéticas, a promover o intercâmbio literário, artístico e científico entre os dois países, a propagar pelo livro, pela imprensa e pela palavra falada a ideia do reconhecimento da URSS, por parte do Brasil, para o reatamento das relações diplomáticas entre os dois países. Os sócios estavam obrigados a combater, por todos os meios, o sentimento de animosidade contra a Rússia. A papeleta de adesão era acompanhada de normas para a utilização da "Biblioteca Ambulante Aurora". ${ }^{83}$

No dia 5 de maio de 1931, a AAR promoveu uma reunião na qual o secreta Antônio Ghioffi notou a presença de Oswald de Andrade, Aristides Lobo, Plínio Gomes de Mello, João Matheus, Antônio Mendes de Almeida, Pedro Motta Lima, João Bueno, Galeão Coutinho, Pereira del Rio e outros. Portanto, pessoas que por suas simples presenças denunciavam o caráter "liguista" daquela sociedade. Nesse dia, por proposta de Aristides Lobo, discutiu-se a ação das autoridades apreendendo livros de literatura russa e prendendo seus editores. Ficou deliberado que a AAR deveria fazer por todos os meios ao seu alcance significativos protestos contra esses atentados à liberdade de comércio e de consciência. Os Amigos da Rússia também nomearam uma comissão para tratar da divulgação do "plano Nowinski" - de acordo com o agente reservado, um estudo de edificação socialista da economia, baseado nos princípios marxistas, aproveitando-se os ensinamentos teóricos de Lênin e Trotski. ${ }^{84}$

Os jornais passaram a denunciar a associação como perigosíssima "camorra de bolchevistas, anarquistas, masorqueiros, comunistas", propondo que se fundasse em São Paulo, para fazer frente aos patrocinadores da Associação dos Amigos da Rússia, uma Associação dos Amigos do Brasil. ${ }^{85}$ 
O Socorro Vermelho ajudava a tarefa dos Amigos da Rússia, embora a seção brasileira tivesse fracassado no objetivo de convertê-lo num órgão de massa: o número de seus membros nunca ultrapassou a 500, dos quais 300 do Rio de Janeiro. Assim, o Socorro terminou por se confundir com as demais organizações revolucionárias do país, não se dedicando ao trabalho de atrair trabalhadores negros e índios para as suas fileiras, apesar de a maioria da população do país ser composta daquelas camadas. A presença dos estrangeiros no SV era mínima, embora existissem três milhões de trabalhadores estrangeiros no país, sobretudo italianos, espanhóis e portugueses. A vida financeira era débil, uma vez que dependia quase exclusivamente das iniciativas financeiras de um grupo israelita. ${ }^{86}$

As associações de defesa proletária constituíram preocupação primordial dos opositores de esquerda e deveriam funcionar em todos os Estados, na forma de comitês regionais. Desde 1927 existia um "Socorro Proletário", cuja CCE se reunia na sede provisória da UTG, na praça da República, no Rio de Janeiro. O objetivo primordial da organização era o de garantir a assistência judiciária, moral e material dos operários, quaisquer que fossem as suas convicções políticas, e que fossem vítimas da reação burguesa. Para tanto, organizaram-se listas de donativos nas quais o proletariado subscrevia auxílios aos companheiros presos. ${ }^{87}$ A ação do SP era evidentemente limitada pelos seus parcos recursos de caixa. Vemos, por exemplo, no movimento financeiro dessa organização, referente aos meses de agosto de 1927 a 15 de junho de 1928, que a quantia de 1:380\$600, arrecadada exclusivamente por meio de listas, auxiliou somente cinco camaradas. As demais despesas referiram-se a telegramas enviados pelo SP, custas processuais e artigos de secretaria e tesouraria. Restaram 9 $\$ 200{ }^{88}$ Embora na miséria mais negra, os oposicionistas não queriam aceitar dinheiro de burgueses. Seria a negação do objetivo fundamental do SP - garantir a assistência judiciária, moral e material dos operários, quaisquer que fossem as suas convicções políticas, e que foram vítimas da reação burguesa. $\mathrm{O}$ proletariado deveria se constituir no fundamento econômico da organização. ${ }^{89}$ Fiel a tal preceito, Víctor escreve a Lívio dizendo ter sabido que o Diário da Noite abrira uma subscrição em favor dos deportados brasileiros, mas não imaginou que fosse uma subscrição pública, na qual "Lyon" (Xavier), membro da liga, estivesse ao lado de Maurício Goulart e de católicos numa lista burguesa, em que figuravam reacionários conhecidos e imperialistas declarados. Portanto, ele e "Maneco" (Manoel Medeiros) aceitariam o dinheiro, mas denunciariam publicamente a manobra política dos subscritores burgueses ${ }^{90} \mathrm{O}$ assunto é objeto de nova carta de "Francisco": Lívio procurara se justificar, localizando, "com olho clínico", o "famoso esquerdismo" de Victor no caso da subscrição, afirmando que ele não era um "militante 
ultraconhecido". No entanto, responde Victor, Lívio já pertencia ao PCB, pois assumia atitudes públicas prefaciando livros de Trótski. ${ }^{91}$

\section{Considerações finais}

A história do mundo do trabalho, em São Paulo, constitui a base para que entendamos a organização dos sindicatos e dos partidos de esquerda, no Brasil. Foi na luta contra a exploração sem limites dos operários, que se formaram lideranças políticas, denunciando a antítese irreconciliável entre o capital e o trabalho, e propondo mudanças estruturais na sociedade.

A capital paulista possuía cerca de 700.000 habitantes e 100.000 operários, por volta da fundação do PCB. Aos operários faltava uma tradição organizatória, capaz de fornecer a necessária base à luta pela defesa dos interesses da classe trabalhadora. Nesse sentido, predominavam as correntes reformistas: socialistas evolucionistas, cooperativistas, movimentos católicos, etc. As ações políticas dessas correntes, em geral, limitavam-se a greves e lutas para a melhoria das condições de vida dos trabalhadores. O conjunto de problemas políticos, sociais e econômicos, advindos do embate entre o capital e o trabalho, era chamado de "questão social". Mais simplesmente e melhor, poderia ser denominada de a existência da pobreza.

As fábricas, os meios sindicais e os partidos políticos estavam em busca de melhorias para os trabalhadores, mas foram se organizando, com o grande influxo de estrangeiros, em especial anarquistas e socialistas, para a formação de uma consciência de classe, capaz de estabelecer a tão sonhada pátria proletária.

Nessa jornada, defrontaram-se com a reação estatal, por meio da criação de órgãos policiais especializados na caça aos infratores. Em 1906 estabeleceu-se em São Paulo a Superintendência da Ordem Política e Social, que deu origem, em 1924, ao DOPS (Departamento de Ordem Política e Social), depois transformado em DEOPS. A batalha externa contra a repressão do Estado, marcada por prisões, torturas e exílios, agravava-se pelas lutas internas das diversas correntes revolucionárias da época, em luta mortal pelo controle da revolução, que se acreditava próxima.

Ação e reação criaram uma multiplicidade de documentos, que nos falam desses tempos duros, mas extremamente fecundos para a formação de uma consciência social, destacada dos poderes estabelecidos.

Nesse ambiente, as ações nefandas de companheiros, aliciados por policiais, contrabalançam-se com a solidariedade individual e coletiva, nacional e internacional, que criou estratégias de socorro mútuo e de resistência, diante do cerco estabelecido pelo Estado contra 
sindicatos, partidos políticos e indivíduos considerados perigosos para a manutenção do statu quo econômico-social do Brasil.

\section{Notas}

${ }^{1}$ CHILCOTE, Ronald H. O Partido Comunista Brasileiro. Conflito e integração . 1922-1972. Rio de Janeiro:

Edições Graal, 1982.

2 BRANDÃO, Octavio. Combates e batalhas: memórias [por] Octavio Brandão. São Paulo: Alfa-Omega, 1978.

${ }^{3}$ CAMPOS, Alzira Lobo de Arruda. "Tempos de Viver": Dissidentes Comunistas em São Paulo (1931-1936). Tese de Livre-docência. FHDSS/UNESP. FRANCA, 1998, p. 246. Mimeo

4 ALVES, Giovanni. O Novo (e Precário) Mundo do Trabalho. Reestruturação produtiva e crise do sindicalismo. São Paulo: BOITEMPO EDITORIAL, 2005, p. 275.

${ }^{5}$ DIAS, Everardo. História das lutas sociais no Brasil, pp. 48-49.

${ }^{6}$ FRANCISCO JOSÉ. "Há ou não há a questão social no Brasil?". A Voz do Gráphico. Rio de Janeiro, 3/12/26, p. 3.

${ }^{7}$ BRANDÃO, Octavio. Combates e batalhas: memórias [por] Octavio Brandão. São Paulo: Alfa-Omega, 1978, p. 208.

${ }^{8}$ Texto ms. assinado por "José Américo". FLBX. CEDEM/UNESP.

${ }^{9}$ O Estado de S. Paulo, 28/11/1889. As notícias sobre greves veiculadas pela imprensa paulista, burguesa ou proletária, para o período de 1889 a 1920, são citadas apud: BEIGUELMAN, Paula. Os companheiros de São Paulo. São Paulo, Ed. Símbolo, 1977.

${ }^{10}$ O Estado de S. Paulo, 1/12/1889.

${ }^{11}$ BEIGUELMAN, Paula. Os companheiros de São Paulo. São Paulo, Ed. Símbolo, 1977, p. 15.

${ }^{12}$ MAFFEI, Eduardo. A Greve. Rio de Janeiro: Paz e Terra, 1978.

${ }^{13}$ Avanti, n. ${ }^{\circ} 22,16 / 17$ de março de 1901.

${ }^{14}$ BASBAUM, Leoncio. História sincera da República, pp. 305-306.

${ }^{15}$ Apud: RIBEIRO, Darcy. Aos trancos e barrancos..., verbete n. 366.

${ }^{16}$ Informações sobre a atividade de Vicente da Costa e Silva. Prontuário do Partido Comunista, n. ${ }^{\circ}$ 2.431, v. 1, doc. n. ${ }^{\circ} 45$, f. 58

${ }^{17}$ Avanti, n. ${ }^{\circ} 20,2 / 3$ e 3/3/1901

${ }^{18}$ DULLES, John W.F. Anarquistas e comunistas no Brasil, p. 26.

${ }^{19}$ O Amigo do Povo, n. ${ }^{\circ} 5,7 / 6 / 1902$.

${ }^{20}$ O Amigo do Povo, n. ${ }^{\circ} 16,22 / 11 / 1902$.

${ }^{21}$ O Amigo do Povo, n. ${ }^{\circ}$ 16, 22/11/1902. Apud: HARDMAN, Francisco Foot. Nem pátria, nem patrão! 2. ed. São Paulo, Brasiliense, 1984, p. 38.

${ }^{22}$ MAFFEI, Eduardo. A greve, p. 134.

${ }^{23}$ RIBEIRO, Darcy. Aos trancos e barrancos. Como o Brasil deu no que deu. 2. ed. Rio de Janeiro: Guanabara Dois, 1985 , verbete n. ${ }^{\circ} 106$.

${ }^{24}$ Apud: MAFFEI, Eduardo. Op. cit., pp. 139-140.

${ }^{25}$ Correio Paulistano, 15/9/1909.

${ }^{26}$ Correio Paulistano, 20/11/1910

${ }^{27}$ DIAS, Everardo. História das lutas sociais no Brasil. 2.ed. São Paulo: Alfa-Omega, 1977, p. 8.

${ }^{28}$ DIAS, Everardo. $\backslash$ Op. cit., pp. 8-9.

${ }^{29}$ N.o $316,6 / 8 / 1911$ e n. ${ }^{\circ} 317,13 / 8 / 1911$.

${ }^{30}$ La Bataglia, n. ${ }^{\circ}$ 317, 13/8/1911.

${ }^{31}$ Hebdomadário anticlerical.

32 Órgão oficial anarquista, também hebdomadário.

${ }^{33}$ Prontuário n. ${ }^{\circ}$ 122, de Edgard Leuenroth, v. 1.

${ }^{34}$ Germinal, n. ${ }^{\circ} 1,16 / 3 / 1913$.

${ }^{35}$ Correio Paulistano, 21/4/1913.

${ }^{36}$ Correio Paulistano, 26/8/1914. 
${ }^{37}$ Correio Paulistano, 27/8/1914.

${ }^{38}$ Avanti, 1/5/1914.

${ }^{39}$ O Estado de S. Paulo, 1. ${ }^{\circ} 3$ de maio de 1919. Apud: DULLES, J.F. Anarquistas e comunistas no Brasil, p.p. 7273.

${ }^{40}$ Sindicato e Estado: São Paulo, Dominus Editora/ Ed. da USP, 1966, pp. 131-142.

${ }^{41}$ MARTINS, José de Souza. Conde Matarazzo, o empresário e a empresa. 2. ed. São Paulo, HUCITEC, 1976, pp. 90-91.

${ }^{42}$ Anarquistas e comunistas no Brasil, p. 438.

${ }^{43}$ Ano III, n. ${ }^{\circ} 28,9 / 10 / 1919$.

${ }^{44}$ Carta de 6/5/1932. Prontuário do Partido Comunista, n.o 2.431, v. 1, doc. n. 26, f. 33.

${ }^{45}$ Prontuário de José Herreiras, n. ${ }^{\circ}$ 89.009. DEOPS/SP.

${ }^{46}$ CARONE, Edgard. Classes sociais e movimento operário. São Paulo, Ática, 1989, p. 145.

${ }^{47}$ SCHMIDT, Afonso. Bom tempo. São Paulo, Brasiliense, 1958, p. 356.

${ }^{48}$ Op. cit., pp.169-171.

49 BASBAUM, Leôncio. História sincera da República. 2. ed., São Paulo, Edições LB, 1962, 2.ํ v., p. 306.

${ }^{50}$ Apresentação. Construindo o PCB (1922-1924), p. 13.

51 SILVA, Hélio. Apresentação, em: CHILCOTE, Ronald H. Partido Comunista Brasileiro. Conflito e Integração. Trad. de Celso Mauro Paciomik. Rio de Janeiro: Edições Graal, 1982, p. 12.

${ }^{52}$ A PROPAGANDA COMUNISTA NO ESTADO DE S. PAULO, doc. cit., f. 73

${ }^{53}$ A PROPAGANDA COMUNISTA NO ESTADO DE S. PAULO, f. 73.

${ }^{54}$ Depoimento de Plínio Melo a Edgard Carone. Apud: Classes sociais e movimento operário, p. 148.

${ }^{55}$ Informe reservado de Antônio Ghioffi. Prontuário do PCB, n. ${ }^{\circ} 4243$, v. 2. DEOPS/SP.

${ }^{56}$ Prontuário da Confederação Geral dos Trabalhadores do Brasil, n. ${ }^{\circ}$ 532, fls. 1-18. DEOPS/SP.

${ }^{57}$ Prontuário de Coripheu de Azevedo Marques, n. ${ }^{\circ}$ 52. DEOPS/SP.

${ }^{58}$ Informe reservado de Antônio Ghioffi à DOPS. S. Paulo, 7/4/31. Prontuário de Coripheu de Azevedo Marques, n. ${ }^{\circ}$ 52. DEOPS/SP.

${ }^{59}$ A Oposição Comunista e as calúnias da burocracia. São Paulo: Edições Luta de Classe, 1931, p. 26.

${ }^{60}$ Boletim de Discussão n. ${ }^{\circ}$ 1. Abril de 1932. (Cópia carbonata realizada em folhas de papel de seda, numeradas de 1 a 9), tese n. ${ }^{\circ}$ 5, fls. 2-4. In: Prontuário de Mário Pedrosa, n. ${ }^{\circ}$ 2020, fls. 23-15. DEOPS/SP.

${ }^{61}$ Prontuário de Antônio Manoel Ribeiro, n. ${ }^{\circ}$ 77, f. 9. DEOPS/SP.

${ }^{62}$ Tese 7, f. 6, doc. cit.

${ }^{63}$ Relatório ao delegado de Ordem Social, Ignácio da Costa Ferreira. São Paulo, 10/10/1931. Prontuário da Federação Sindical Regional de São Paulo ou Federação Regional Sindical, n. ${ }^{\circ} 880$, v. 2, doc. n. ${ }^{\circ}$ 57. DEOPS/SP.

${ }^{64}$ Carta de José Oiticica. Rio de Janeiro, 11/5/1931.Ms. Prontuário de José Oiticica, n. ${ }^{\circ}$ 860. DEOPS/SP.

65 Informe reservado do agente "Guarany". São Paulo, 24/12/34. Prontuário de José Oiticica, n. 860. DEOPS/SP.

66 "Federação Comunista Libertária", in: Prontuário da Confederação Geral dos Trabalhadores do Brasil, n. ${ }^{\circ} 532$, f. 38. DEOPS/SP.

${ }^{67}$ Prontuário de Lucas Gabriel, n. ${ }^{\circ}$ 97772. DEOPS/SP.

${ }^{68}$ MALATESTA, Errico. Em torno de uma polêmica. Anarquismo Libertário e Revisionismo Autoritário. São Paulo, 1932, p.p. 1-17. In: Prontuário de Lívio Abramo, n. ${ }^{\circ} 2238$. DEOPS/SP.

${ }^{69}$ Informe reservado de Antônio Ghioffi, de 19/2/31, in: Prontuário de Francisco Quesada, n. o 497, f. 1. DEOPS/SP.

${ }^{70}$ Declarações existentes no prontuário de João da Costa Pimenta, n. ${ }^{\text {2 } 217, ~ f . ~ 30 . ~ D E O P S / S P . ~}$

${ }^{71}$ Informe reservado de João Guerra a Ignácio da Costa Ferreira, delegado da Ordem Social. São Paulo, 14/2/31. Prontuário de Afonso Schmidt, n. ${ }^{\circ}$ 11. DEOPS/SP .

${ }^{72}$ Relatório ao Delegado de Ordem Social. S. Paulo, 10/10/1931, prontuário n. ${ }^{\circ} 880$, v. 2, doc. n. ${ }^{\circ} 57$. DEOPS/SP.

${ }^{73}$ Boletim da U.T.G. Prontuário da Federação Sindical Regional de São Paulo, n. ${ }^{\circ}$ 880, v. 1. DEOPS/SP.

${ }^{74}$ Carta de Antônio Ghioffi ao delegado de Ordem Social. São Paulo, 3/8/31. Loc. cit., f. 21.

${ }^{75}$ ROIO, José Luiz Del. 1. ${ }^{\circ}$ de Maio. Cem anos de luta. 1886-1986. Org. pelo Centro de Memória Sindical. São Paulo: Global, 1986, p. 143. 
76 Carta de "Antônio" (Aristides Lobo), secretário-geral da LC. São Paulo, 29/9/31. Prontuário da Federação Regional Sindical, n. ${ }^{\circ} 880$, v. 1. DEOPS/SP.

${ }^{77}$ Informações sobre Arsênio Palacios. Prontuário n. ${ }^{\circ}$ 1507, doc. 1, f. 3. DEOPS/SP.

${ }^{78}$ Relatório ao delegado de Ordem Social. S. Paulo, 10/10/1931, prontuário n. ${ }^{\circ} 880$, v. 2, doc. n. ${ }^{\circ}$ 57. DEOPS/SP

79 "Relatório apresentado pela Comissão Executiva à Primeira Conferência Nacional da Liga Comunista". FLBX CEDEM/UNESP.

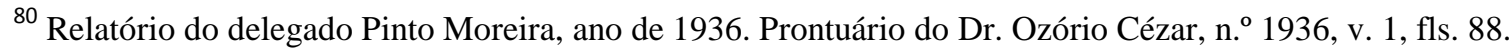

${ }^{81}$ Prontuário de Galeão Coutinho, n. ${ }^{\circ}$ 163, f. 19. DEOPS/SP.

${ }^{82}$ Associação de Amigos da Rússia. São Paulo. Relação dos sócios em 31/3/31. FLBX. CEDEM/UNESP.

${ }^{83}$ Inscrição de Aristides Lobo, como sócio n.o 14 da Associação de Amigos da Rússia. FLBX. CEDEM/UNESP.

${ }^{84}$ Informe reservado de Antônio Ghioffi. São Paulo, 5/5/31. Prontuário de Plínio Gomes de Mello, n. ${ }^{\text {3 }} 385$, f. 21. DEOPS/SP.

85 “Carta aberta a 'um moço bem comportado', a propósito da Associação dos Amigos da Rússia”. Recorte de jornal em: prontuário citado, fls. 11-10.

${ }^{86}$ PEREIRA, Astrogildo. "Carta aos Camaradas". Documento n. ${ }^{\circ}$ 9, Prontuário n. ${ }^{\circ} 44$, fls. 35-32. DEOPS/SP.

${ }^{87}$ Carta ao "companheiro Carlos Villanova", escrita em papel timbrado dos advogados Max Leitão, Octacílio Pereira e Hahnemann Guimarães, dando conta da fundação do Socorro Proletário. FLBX . CEDEM/UNESP.

${ }^{88} O$ Alfaiate (jornal). Rio de Janeiro, 18/7/28, n. ${ }^{\circ} 43$, ano VI. ASMOB. CEDEM/UNESP.

${ }^{89}$ Carta ao companheiro Carlos Villanova. FLBX . CEDEM/UNESP.

${ }^{90}$ Montevidéu, 31/10/31. FLBX . CEDEM/UNESP.

${ }^{91}$ Bariri, 23/11/31. FLBX . CEDEM/UNESP.

\section{Referências Bibliográficas}

ALVES, Giovanni. O Novo (e Precário) Mundo do Trabalho. Reestruturação produtiva e crise do sindicalismo. São Paulo: BOITEMPO EDITORIAL, 2005.

ARENDT, Hanna. Da Revolução. Trad. de Fernando Dídimo Vieira. 2. a ed. São Paulo: Ática; Brasília: Ed. Universidade de Brasília, 1990.

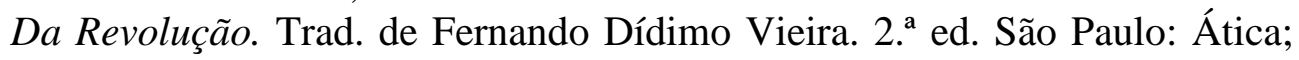
Brasília: Ed. Universidade de Brasília, 1990, p. 48.

BASBAUM, Leoncio. História sincera da República. 2. ed. São Paulo/ Coleção Temas Brasileiros. Editora Edaglit, 1962.

BEIGUELMAN, Paula. Os companheiros de São Paulo. São Paulo, Ed. Símbolo, 1977.

BRANDÃO, Octavio. Combates e batalhas: memórias [por] Octavio Brandão. São Paulo: Alfa-Omega, 1978.

CAMPOS, Alzira Lobo de Arruda. "Tempos de Viver": Dissidentes Comunistas em São Paulo (1931-1936). Tese de Livre-docência. FHDSS/UNESP. FRANCA, 1998, p. 246. Mimeo.

CAMPOS, Alzira Lobo de Arruda. Estrangeiros e ordem social (São Paulo, 1926-45). Revista Brasileira de História, v. 17, 1997, p. 201-237.

CARONE, Edgard. Classes sociais e movimento operário. São Paulo, Ática, 1989.

CHILCOTE, Ronald H. O Partido Comunista Brasileiro. Conflito e Integração. 1922-1972. Trad. de Celso Mauro Paciomik. Rio de Janeiro: Edições Graal, 1982.

DIAS, Everardo. História das lutas sociais no Brasil. São Paulo: Temas Brasileiros n. 8, Editora Edaglit, 1962. 
DULLES, John W. F. Anarquistas e comunistas no Brasil. 1900-1935. Rio de Janeiro: Nova Fronteira, 1977.

HARDMAN, Francisco Foot. Nem pátria, nem patrão! 2. ed., São Paulo: Brasiliense, 1984. Jornal O Estado de S. Paulo. Edições de: 1/12/1889; 20/6/1917; 30/6/1917; 6/7/1917.

MAFFEI, Eduardo. A Greve. Rio de Janeiro: Paz e Terra, 1978.

MARTINS, José de Souza. Conde Matarazzo, o empresário e a empresa. 2. ed. São Paulo, HUCITEC, 1976.

RIBEIRO, Darcy. Aos trancos e barrancos. Como o Brasil deu no que deu. 2. ed. Rio de Janeiro: Guanabara Dois, 1985.

ROIO, José Luiz Del. 1. ${ }^{o}$ de Maio. Cem anos de luta. 1886-1986. Org. pelo Centro de Memória Sindical. São Paulo: Global, 1986.

SCHMIDT, Afonso. Bom tempo. São Paulo, Brasiliense, 1958.

SILVA, Hélio. Apresentação, em: CHILCOTE, Ronald H. O Partido Comunista Brasileiro. Conflito e Integração. Trad. de Celso Mauro Paciomik. Rio de Janeiro: Edições Graal, 1982. SIMÃO, Azis. Sindicato e Estado: São Paulo, Dominus Editora/ Ed. da USP, 1966. 